\title{
Scientists avert new GMO crisis
}

The crop biotechnology community has started to act preemptively in an effort to temper the overexuberance with which the lay press has seized on recent papers against genetic modification. Following an announcement in mid-November that a paper entitled "Cauliflower mosaic viral promoter-a recipe for disaster" was to be published in the next issue of Microbial Ecology in Health and Disease, prominent plant scientists circulated their comments and criticisms rapidly on e-mail networks. The plant researchers uniformly damned the paper. Their individual responses varied from detailed scientific critique to rebukes directed at the journal's editors, to ridicule of the paper itself. The episode demonstrates that researchers in this field are primed to damp down undeserved adverse publicity concerning GM plants.

The paper in question was not original research but an unrefereed opinion piece written by Mae-Wan Ho and Angela Ryan of the Open University (Milton Keynes, UK) and Joe Cummins of the University of Western Ontario (Canada). The authors discuss the safety implications of recent research on the cauliflower mosaic virus (CaMV) 35S promoter, pointing out (perfectly correctly) that the promoter is in practically all transgenic crops currently released commercially or undergoing field trials.

After arguing that it is "highly likely" that the CaMV $35 \mathrm{~S}$ promoter will take part in horizontal gene transfer and recombination and "cause large-scale genomic rearrangements in the process," the authors go on to imply that the promiscuity of the CaMV promoter could enable it to trigger cancer. The promoter, they say, "has the possibility of promoting inappropriate over-expression of genes in all species to which it happens to be transferred. One consequence of such inappropriate over-expression of genes may be cancer." Unsurprisingly, given this conclusion, the authors strongly recommend that "as a precautionary measure ... all transgenic crops containing CaMV 35 S or similar promoters that are recombinogenic should be immediately withdrawn from commercial production or open field trials." They also suggest that products from such crops should also be immediately withdrawn from sale and use."

The paper, which was available in electronic form (www.scup.no/mehd/ho), was attacked on many fronts by scientists. Virologist Barbara Hohn from the Friedrich Miescher Institute (Basel, Switzerland) admitted to being "terribly irritated" by it. She says the authors inaccurately cite her work, attributing characteristics to the CaMV 35S promoter based on work Hohn and colleagues had performed on the CaMV 195 promoter.

Perhaps the main criticism, however, was that the ubiquity of the CaMV 35 S promoter and related sequences means that its presence in GM plants is simply irrelevant. Roger Hull, an emeritus research fellow at the John

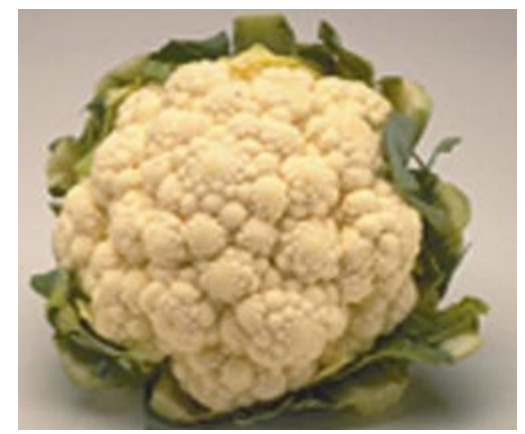

Cauliflower mosaic virus: Cause for concern?

Innes Institute (Norwich, UK) and one of the discoverers of the CaMV 35 S promoter, for instance, had estimated that about $10 \%$ of cauliflowers and cabbages at his local market were infected with CaMV. That data were not new, having been gathered in the late 1980s as part of the approval process for the release of the first recombinant plant pathogen in the UK. Furthermore, a typical infected cell contained around 100,000 copies of the virus and its genome. Transgenesis would add but one to five copies of the $35 \mathrm{~S}$ promoter. In addition, says Hull, plants are "loaded" with potentially mobile DNA - such elements making up close to $50 \%$ of the genome in some cereals. Historically, therefore, humans have been consuming CaMV and its $35 \mathrm{~S}$ promoter at levels that are over 10,000 times greater than those in uninfected transgenic plants. Jim Astwood of Monsanto (St. Louis, MO) points out that it was precisely this line of argument that led the US Department of Agriculture (Washington, DC) to determine early in its regulation of recombinant plants that $35 \mathrm{~S}$ promoter-containing plants represent a negligible risk of producing new viruses or causing environmental damage.

Having consulted a number of the UK's leading plant virologists, Chris Leaver from the University of Oxford rejected the suggestion made by Ho et al. that CaMV $35 \mathrm{~S}$ could be transferred from plants to green algae, yeast, and Escherichia coli on similar grounds. He noted that such a transfer had not occurred even though, throughout history, humans had consumed huge quantities of the CaMV 35S promoter by "eating our greens." He also rejected as "pure fiction, and lies" the suggestion that CaMV might reactivate dormant hepatitis B virus or create new viruses because there was a phylogenetic relationship between CaMV and human hepadnaviruses (such as hepatitis B). Leaver points out the obvious defect in this argument: the two viruses never replicate in the same cells; CaMV replicates in plants and hepatitis B in animals.

With considerable irony, several critics of the paper suggested that Ho et al. had not gone far enough in calling for a ban on transgenic crops containing the $35 \mathrm{~S}$ promoter. "Let's stop eating plants and animals altogether," said Barbara Hohn. "It's a shame we did not have this information millions of years ago. It would have been so easy to avoid the perils of life."

The editor of Microbial Ecology in Health and Disease, Tore Midtvedt, a professor at the Karolinska Institute for the past 18 years, was aware the article would be controversial. "My intention is to stimulate debate," he says. Part of his editorial strategy when he became editor-in-chief two years ago, he says, was to make the journal "an open place where people can come up with ideas." Midtvedt cites the editorial remark made recently in the Lancet when that journal published some of the work by Arpad Pusztai on rats fed lectin-containing transgenic potatoes: "If the paper is not published, it will be claimed that there is a conspiracy to suppress information." Midtvedt believes, however, that readers would know that the paper was not original research and was unrefereed. The non-peer-reviewed articles are "always commented on previously in the editorial section," he says.

However, the journal's publisher, the Scandinavian University Press, does appear to be guilty of misrepresentation of its own content. Their press release is entitled "New Research Results on Genetically Modified Organisms" and speaks of Ho and colleagues as "the scientists behind the research," both statements being difficult to reconcile with the article's status as an opinion piece. Roger Hull is marshaling the various comments in order to submit a formal response to Microbial Ecology in Health and Disease.

John Hodgson 